\title{
Teaching reform and practice of optoelectronic technology curriculum
}

\section{Min Qian, Dan Wu, Yan Ye, Guiju Zhang, Jihua Gu}

Min Qian, Dan Wu, Yan Ye, Guiju Zhang, Jihua Gu, "Teaching reform and practice of optoelectronic technology curriculum," Proc. SPIE 11143, Fifteenth Conference on Education and Training in Optics and Photonics: ETOP 2019, 1114337 (2 July 2019); doi: 10.1117/12.2523449 


\title{
Teaching Reform and practice of Optoelectronic Technology Curriculum
}

\author{
Min Qian ${ }^{\mathrm{ab}}$, Dan $\mathrm{Wu}^{* \mathrm{ab}}$, Yan Ye ${ }^{\mathrm{b}}$, Guiju Zhang ${ }^{\mathrm{b}}$, Jihua $\mathrm{Gu}^{\mathrm{b}}$, \\ ${ }^{a}$ Wenzheng College of Soochow University, Suzhou 215104, China; ${ }^{b}$ School of Optoelectronic \\ Science and Engineering, Soochow University, Suzhou, 215006, China
}

\begin{abstract}
Driven by the idea of students-centered, aptitude-oriented cultivation, that is to educate each student according to his natural ability, the course content of the optoelectronic technology is optimized and integrated, and the extension project is added according to the ability of different students, which involves the scientific frontier and the practical training. To ensure the final implementation of the course reform, the assessment modes are designed and students are allowed to select their assessment test according to their interest and ability, just like a set menu. No matter what kind of assessment modes the students choose, all classmates are required to give an oral presentation about their extension project. The realization of multifaceted assessment enhances students' participation and devotion to the course.
\end{abstract}

Keywords: optoelectronic technology, multifaceted assessment, extension project

\section{INTRODUCTION}

As one of leading industries of the 21st century, optoelectronic industry plays an important role with the development of science and technology. "Optoelectronic Technology" is one of the fundamental courses of optoelectronic science and Engineering. In the past, the teaching mode of Optoelectronic Technology often paid too much attention to related basic theoretical knowledge and formula derivation. In addition, due to the influence of traditional teaching modes, the teaching process still stays in the teacher's classroom teaching, The students passively learn and the teachers dully give lessons, which leads to the lack of class-participation and practical application of the students. Driven by the concept of students-centered, aptitude orientated cultivation, we have reformed the content of courses and the methods of assessment, this paper is arranged as follows, In sec. 2, the content of the Optoelectronic Technology is reframed and the scientific frontier and the practical training are added. Two different assessment modes are designed. In sec. 3, the teaching means during the course are proposed. A discussion concludes the paper.

\section{REFORM MEASURES}

\section{1 formulate a classified training plan and adjust the content of the course}

The "Optoelectronic technology" course covers a wide range of knowledge, and the contents of each chapter are relatively independent. Students often reflect that this course is "miscellaneous" and "difficult". In order to solve the problem of the lack of logical relations in the content of the chapter, a knowledge framework for Optoelectronics technology is created, as shown in Figure 1. The main line of the theoretical curriculum content is the light source, information loading, transmission channels, detection, signal processing, and display. The logical connection between chapters has been added, and the contents of the integrated course have been rearranged. The extension project is added to enhance students' participation and devotion to the course.

On the basis of completing the basic classroom teaching, we try to teach students according to their own needs, and divide the expansion phase of the course into two parts, the scientific frontier and the practical training. Students are encouraged to choose the extension stage based on their own interests and expertise. The scientific frontier requires students to choose a direction to expand the contents of the syllabus and find relevant research frontier through network resources and finish the task in the form of an overview report. The practical training requires students to complete the works with the guidance of the teacher. Some extracurricular projects in recent three years are shown in Table 1. Students are also encouraged to propose the name of the works according to their own interests and submit the work plan.

*wud@suda.edu.cn

Fifteenth Conference on Education and Training in Optics and Photonics: ETOP 2019, edited by

Anne-Sophie Poulin-Girard, Joseph A. Shaw, Proc. of SPIE Vol. 11143, 1114337 · (c) 2019

SPIE, ICO, IEEE, OSA · CCC code: 0277-786X/19/\$18 · doi: 10.1117/12.2523449 
Teachers analyze students' problems in the process of completing their works, help eliminate problems in order to successfully complete their works. Finally, both the scientific frontier and the practical training require students to give an oral presentation in the classroom.

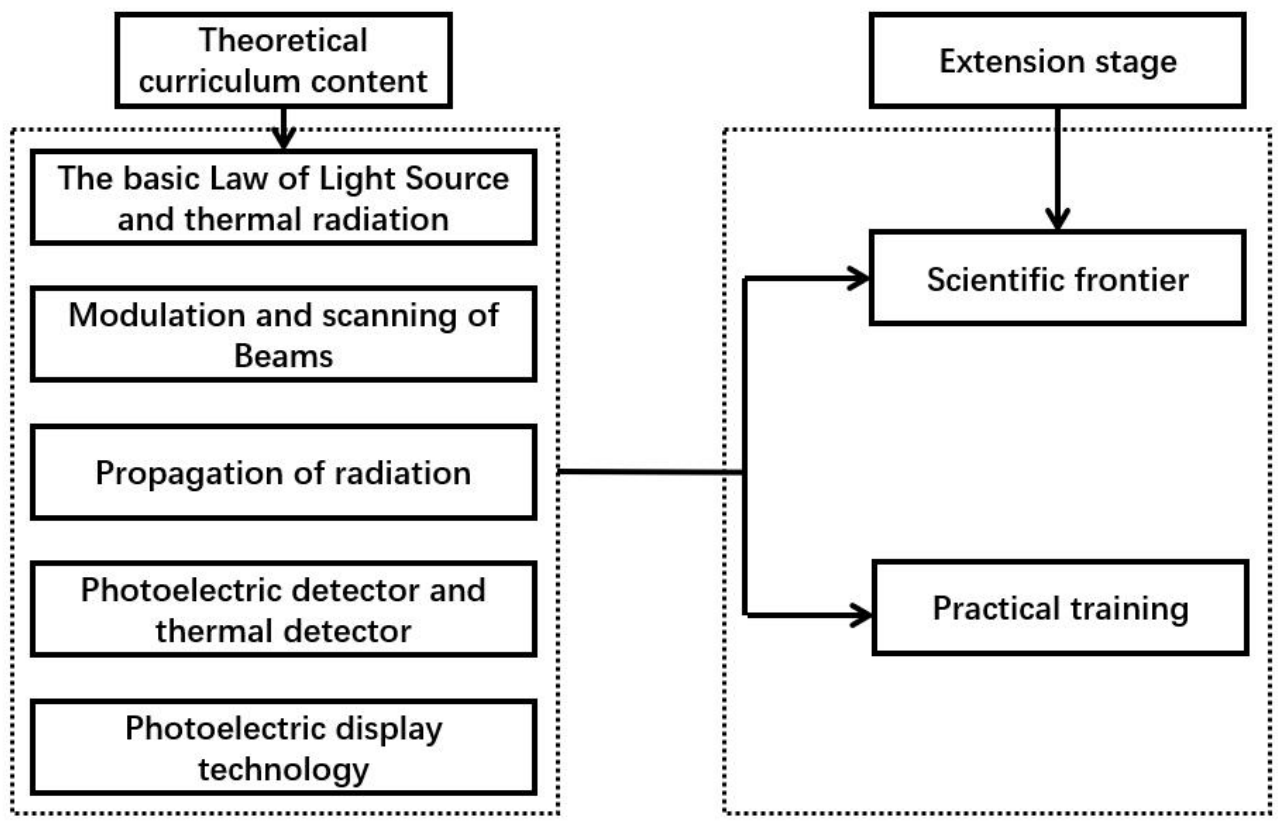

Figure 1. knowledge framework for Optoelectronics technology

Table 1. List of partial extracurricular projects in recent three years.

\begin{tabular}{|c|c|}
\hline Sequence number & Title \\
\hline 1 & Design of light control switch \\
\hline 2 & Design of traffic lights \\
\hline 3 & Design of photoelectric alarm \\
\hline 4 & Design of pyroelectric alarm \\
\hline 5 & Design of silicon photocell photometer \\
\hline 6 & Analysis and Design of camera auto-exposure Circuit \\
\hline 7 & Design of photoelectric counter \\
\hline 8 & Design of Smoke alarm \\
\hline 9 & Design of LED dot matrix display \\
\hline 10 & Design of intelligent LED lamp \\
\hline 11 & Design of LED music fountain \\
\hline 12 & Design of Audio-optic electronic organ \\
\hline 13 & Design of intelligent home environment monitor \\
\hline 14 & Design of automatic light tracking system \\
\hline
\end{tabular}




\subsection{Reform the assessment method}

To ensure the effectiveness of the course reform, the assessment modes are designed and students are allowed to select their assessment method according to their interest and ability, just like a set menu (shown in Table 2). The reformed curriculum assessment changed the traditional single assessment method, which emphasizes excessively on the rigid closed-book examination. Combining the curriculum content and teaching reform of "Optoelectronics Technology", the specific assessment includes usual performance (20\%), which relates to the attendance and school assignments of the classroom teaching. Students are encouraged to choose the extension stage between the scientific frontier and the practical training. For students who choose scientific frontier as their extension, a closed-book exam $(30 \%)$ and a review report (30\%) are needed as their theoretical assessment and extension assessment. For students who choose the practical training as their extension, the open-book examination (25\%) and practical works $(40 \%)$ are needed as their theoretical assessment and extension assessment. For this assessment method, more practical ability and comprehensive quality are emphasized. No matter what kind of assessment modes the students choose, all classmates are required to give an oral presentation about their extension project (15\%). All the classmates can ask the presenter questions and participate the discussion. Therefore, the realization of multifaceted assessment enhances students' participation and devotion to the course. Through such curriculum reform, the curriculum is standardized and talents are personalized. Students who have interests in scientific knowledge can choose to finish review reports and take closed-book examination. Students who are good at practicing can choose to complete the practical works and take the open-book examination. Students make full use of extra-curricular time, improve professional skills, become active learner.

Table 2. Assessment content, assessment methods and proportion.

\begin{tabular}{ccc}
\hline $\begin{array}{c}\text { Assessment content } \\
\text { Usual grades }\end{array}$ & Assessment methods & Proportion \\
Theoretical assessment & Open-book exam (the practical training) & 25 \\
& Closed-book exam (the scientific frontier) & 35 \\
Extension assessment & Review report design capabilities (the scientific frontier) & 30 \\
& Answering questions and participating in the discussion & 15 \\
\hline
\end{tabular}

\subsection{Improve the teaching methods and means}

Teaching materials have a certain degree of timeliness, it is impossible to include the latest scientific and technological developments. This requires teachers to browse a lot of scientific and technological information and understand the current professional dynamics. When introducing LEDs, we can introduce the use of blue LEDs and red LED to illuminate rice in the laboratory to increase the yield; When introducing photomultiplier tubes, it is necessary to introduce HAMAMATSU's series of PMTs and the PMT array used in the experimental device built to measure proton decay in Kamioka, Japan; When introducing the display technology, we can introduce CRT, LCD, PDP and laser display technology are introduced

When introducing infrared photoelectric sensors, interactive classroom teaching content can be based on the design of "solar photoelectric smart car" to realize the tracking function of smart car. Students can use cameras, photo-infrared tube sensors, lasers, and special color sensors to achieve four solutions. The track can be an eight-shaped, four-square, Oval, and so on. The background of the trace can be the simplest white background black line-white background green line-green green line and so on. In the interactive course teaching, when discussing the feasibility of the proposal, we can start with the simplest black line on the white background and the elliptical trajectory. After the students' discussion and proposed solutions, they gradually increase the difficulty of the discussion, such as replacing the track photoelectric sensor. Different optoelectronic devices have different ways of converting optical signals, amplifying the signal, and processing the error. Once the equipment is replaced, the digital conversion and the single-chip machine program are 
required to be redesigned. In the intense discussion among students, students are slowly guided from shallow to deep, from easy to difficult to propose solutions, find problems to revise plans, solve problems, and finally use the solutions discussed in the classroom, and then independently design their own works. Through this interactive classroom teaching method, students can learn, think, and do, drive students' inherent professional potential, realize the harmony and unity of thinking and practice, and truly improve students' engineering quality.

\section{EXTRACURRICULAR PROJECTS}

\subsection{Purposes}

The purposes of extracurricular projects are listed as follows. Firstly, the students are trained to learn the basic idea of optoelectronic system design and basic methods, and master all kinds of design tools. They should maser the basic skills such as analog circuits, digital circuits, $\mathrm{C}$ language programming and theory and interface technology of single chip microcomputer. Secondly, the project practice could give full play to the personality of students and deepen their understanding of optical and circuit-related knowledge. Finally, by designing, installing and debugging the actual photoelectric systems, the comprehensive abilities of using theoretical knowledge to analyze and solve problem are obtained. During this process, the scientific rigorous style and good habits would be formed.

\subsection{Selection of Topics}

Firstly, the topic should be able to combine optoelectronics and circuit, including photoelectric sensor, analog circuit design, digital circuit design, microprocessor, simulation and application programming, and PCB design, circuit welding and debugging. Secondly, the topic should be suitable for practical teaching and inspiration innovation, and the topic content should not be too simple. The topics' progressiveness, comprehensiveness and practicality should be payed more attention.

Fig.2 shows the project finished by the students. It is a LED music fountain, which has three Basic functions:1. Input and play music in computer and mobile phone through audio cable;2. There are 8 LED color lights with spectrum, flashing with music;3. Music stops and the water jet motor stops working.

Fig. 3 shows the design of audio-optic electronic organ, which has eight notes through the button and can play the music; LED lights up with music

Fig.4 shows the photoelectric detection smart car finished by students, which can achieve infrared remote control, infrared tracking, infrared obstacle avoidance.

Fig.5 shows the automatic light tracking system, which can track the sunlight automatically.

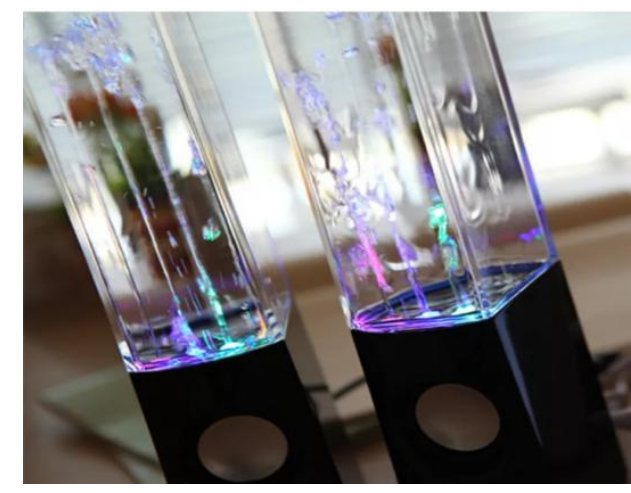

Figure 2. LED music fountain.

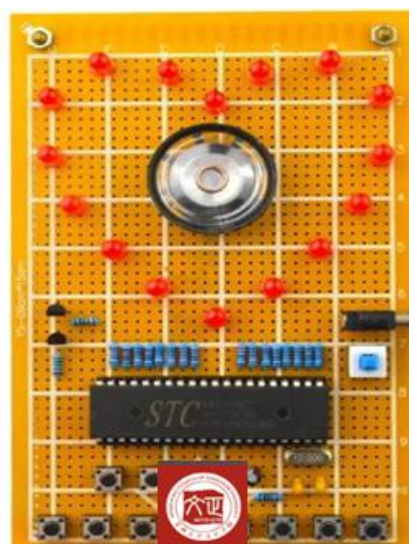

Figure 3. audio-optic electronic organ. 


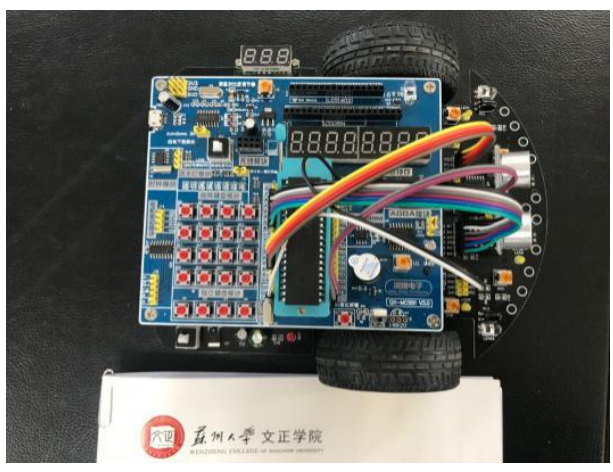

Figure 4. photoelectric detection smart car.

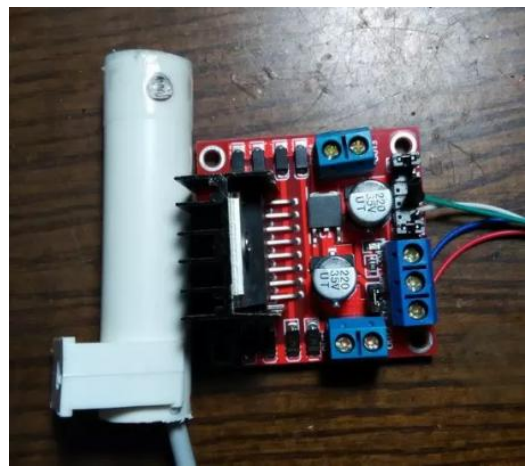

Figure 5. automatic light tracking system.

\subsection{The design of logo}

We divide the students into groups with 3-4 members, and each group elect a team leader who should be responsible for the assignment of tasks and the summary of the group's work, and write a weekly work log. Each group will design a personality logo to represent the selected topic. Such logo design exercises the members' team cooperation , copywriting conceptual ability, and aesthetic ability.

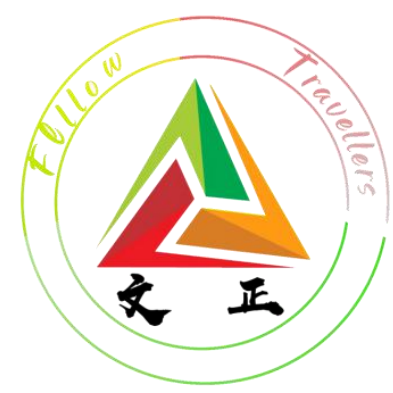

Figure 6. The logo for the design of traffic lights

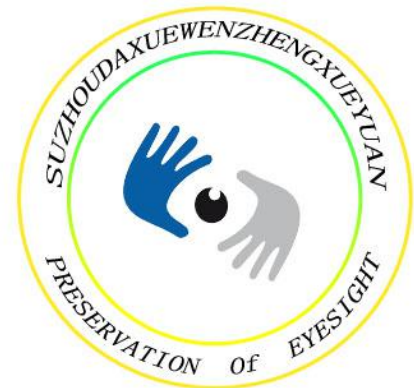

Figure8. The logo for the design of intelligent LED lamp

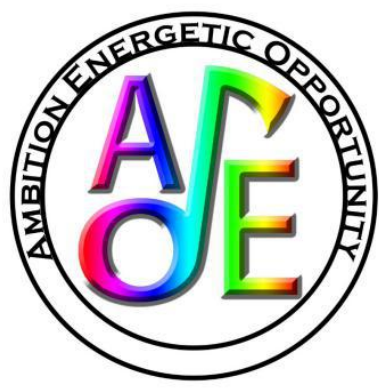

Figure7. The logo for the design of audio-optic electronic organ

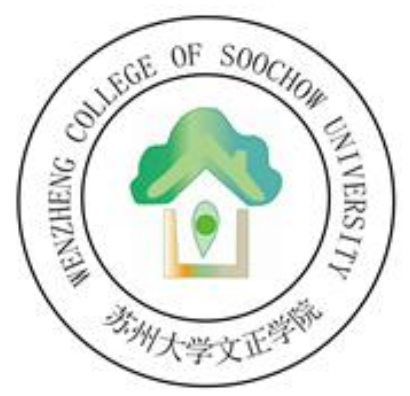

Figure9. The logo for the design of intelligent home environment monitor 
Students' explanation of the inspiration of Fig. 6:The meaning of fellow and traveller: the process of doing this project is like a trip. The team members are the traveling companions of this trip. They go together and help each other to make progress together. Traffic lights can be understood as the landmarks in travel, so it also fits our subject content. Triangle is a stable structure, and the three angles have the three colors of the signal lamp respectively, that is red,green, and orange. The three angles are sharp and angular, which represent the members of our group with their own characteristics. The circle at the outside represents our collective, embracing all the edges and corners of the angles.

Students' explanation of the inspiration of Fig. 7: audio-optic electronic organ with the acronym is AOEO.Therefore, we use the three letters of "AOEO" in the logo.The colored letters represent the seven different colors of the white light. The initial letter of the three words at the outer circle of the logo is "A", "O" and "E", which further embodies the subject. "Ambition" "Energetic" "Opportunity" is a symbol of our "AOEO", Which reflect active, energetic, forward spirit.

Students' explanation of the inspiration of Fig. 8: The letter on the top of the team emblem is the Chinese pinyin of "Wenzheng College of Soochow University", which means that we never forget that we are students of Wenzheng. The English letter under the team logo is "vision protection", which represents our research subject.Two hands in the middle of the logo means eyesight protection. The thumb of two hands and the pupil in the middle make up one eye.The whole pattern implies the importance of vision protection.

Students' explanation of the inspiration of Fig.9 : green roof represents comfortable environment, In the middle is an eye which represents an ongoing intelligent home environment test

\section{CONCLUSIONS}

Through the introduction of extra-curricular extension and assessment innovation, students greatly improve their interest in learning and broaden their knowledge. Optoelectronics itself is a technical and applied discipline. Our reform goal is to further enhance the training of optoelectronic specialty. Therefore, we combine photoelectric scientific frontier and practical works, innovate the teaching content and assessment method, pay attention to the cultivation of students' innovative ability, scientific literacy, scientific research interest, and professional interest. We give full play to students' subjective initiative, focus on students' own design, give full play to students' potential, and cultivate students' independence and comprehensive practical ability. Students can put forward practical design plans themselves and carry out training in the design of optical and electronic circuits for small simple systems. The relatively good works of students can be displayed by the teacher during the next class, thus stimulating the interest of the students and ensure the continuity of the teaching reform.

Furthermore, the reform of assessment modes allows students to select their assessment test according to their interest and ability, just like a set menu, which greatly enhances students' participation and devotion to the course.

\section{REFERENCES}

[1] Cun, Y.L, Zhou, Q., Chen, Z.G., "The new 'project + contest + certification' talents training mode of electronics specialty in local universities," The Guide of Science \& Education, 65-67 (2015).

[2] Liu, Y.F., Li, Q., Guo, s. L, and Xu, J., "Developing EDA integrated experimental platform and cultivating students' ability on engineering education," Research and Exploration in Laboratory, 26(8), 63-65(2007).

[3] Pang, H., "Discussion and practice on the teaching reform of 'electric circuit analysis' course," China Electric Power Education, 58-59 (2009).

[4] Liu, J. c., Mao, J. B., Yang, M. w., "Exploration and practice of subject construction of electronic science and technology," Journal of Hefei University of Technology (Social Sciences), 22(6), 138-141 (2008). 